\title{
Introduction to the Special Issue on "The Intersection Between Industrial Organization and Healthcare Economics"
}

\author{
Christopher M. Snyder ${ }^{1}$ - Victor J. Tremblay ${ }^{2}$
}

Published online: 28 March 2018

(C) Springer Science+Business Media, LLC, part of Springer Nature 2018

\begin{abstract}
This article introduces the special issue on the intersection between industrial organization and healthcare economics. This intersection has received increasing research interest, growing from $2 \%$ of the industrial-organization literature in 1991 to $6 \%$ in 2016. We describe the nine included articles, which cover a range of healthcare markets that include hospital services, insurance, and pharmaceuticals.
\end{abstract}

Keywords Industrial organization $\cdot$ Healthcare $\cdot$ Pharmaceuticals $\cdot$ Insurance · Hospital

JEL Classification I11 (Analysis of Health Care Markets) - L65 (Manufacturing: Drugs) $\cdot$ I13 (Health Insurance)

\section{Explosion of Research Interest}

This special issue is located at the intersection between the subfields of industrial organization (IO) and healthcare economics. As Fig. 1 documents, this intersection

Electronic supplementary material The online version of this article (https://doi.org/10.1007/ s11151-018-9628-x) contains supplementary material, which is available to authorized users.

Christopher M. Snyder

chris.snyder@dartmouth.edu

Victor J. Tremblay

v.tremblay@oregonstate.edu

1 Department of Economics, Dartmouth College, 301 Rockefeller Hall, Hanover, NH 03755, USA

2 Department of Economics, Oregon State University, 430 Bexell Hall, Corvallis, OR 97331, USA 


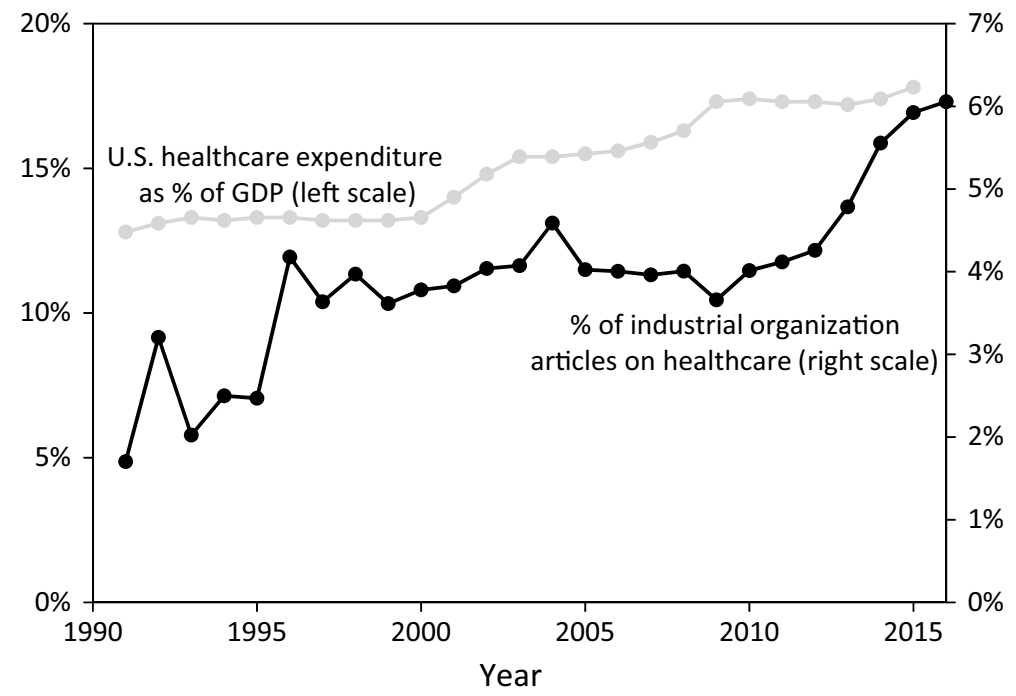

Fig. 1 Growth in relevance of healthcare as an IO topic Sources: The grey curve is based on the Excel table NHE15_Summary.xls, retrieved on September 27, 2017 from https://www.cms.gov/Research-Stati stics-Data-and-Systems/Statistics-Trends-and-Reports/NationalHealthExpendData/NationalHealthA ccountsHistorical.html. The black curve is based on authors' count of articles returned by EconLit searches over all Journal of Economic Literature subject descriptors in the L (industrial organization) category each year, calculating the percentage of those articles mentioning "health." The authors conducted the counts on September 27, 2017, using the version of EconLit for American Economic Association Members available at https://www.aeaweb.org/econlit/econlit-for-members

is a "hot" research area. The black curve plots the percentage of the IO literature (as proxied by articles indexed by EconLit having an L, the code for IO, in one of their subject descriptors) on a healthcare topic (as proxied by the mentioning "health" somewhere in the paper). Fewer than $2 \%$ of the IO articles that were published in 1991 - only 23 of them—were on healthcare. By 2016, the IO literature itself had grown almost 10 fold to over 10,000 articles. The healthcare segment constituted a growing share-6\%-of this growing literature, with over 600 articles in the intersection published that year. Notice the particularly rapid growth in the relative attention paid by IO to healthcare over the last five years. ${ }^{1}$

Various explanations for this explosion in interest in the IO/healthcare intersection come readily to mind: one is that a steadily growing fraction of the economy is devoted to healthcare. This is documented by the grey curve in Fig. 1, which shows that between 1991 and 2015 the percentage of U.S. GDP that was devoted to healthcare expenditures grew by five percentage points: from nearly $13 \%$ to nearly $18 \%$. It is natural that IO economists' interest should grow in proportion to the size of the industry in question.

\footnotetext{
${ }^{1}$ For excellent surveys of various segments of the healthcare market, see Gaynor et al. (2015) on hospital-services and insurance markets and Scherer (2000) on pharmaceuticals.
} 
A second explanation is that a growing share of research and development (R\&D) expenditure is being poured into the healthcare sector: From 1991 to 2015, the share of U.S. R\&D in the healthcare sector grew from 16 to $32 \% .^{2}$ It is natural for IO economists-especially those specialists in innovation and technological changeto train their lens on the dynamic healthcare sector.

A third explanation is that important healthcare reforms-such as the U.S. Affordable Care Act of 2010 (popularly known as "Obamacare")—were contemplated or enacted during the period; these reforms had interesting IO implications in addition to sweeping ramifications for the overall economy. It is natural for IO economists to want to contribute to the analysis of these policies.

We suggest another reason for the explosion in the IO/health intersection: the dawning realization that healthcare markets - unique as they are-are not necessarily more distinctive than airlines, electricity, or hundreds of other markets that IO economists have studied for decades; see Chandra et al. (2016) for an argument along these lines. The tools that have been honed by IO economists in their analysis of these other markets-with all due care to understand the relevant institutional details in each new setting — can be fruitfully applied to health markets.

\section{Organization of the Special Issue}

The special issue can be neatly organized into three parts according to a scheme that perhaps only an IO economist would love: the North American Industry Classification System (NAICS) codes.

The four empirical articles in Part I study different aspects of hospital operations (NAICS code 622): McCarthy and Huang (2017) seek to explain the dramatic change in the hospital-doctor relationship over the last decade, with doctors increasingly employed by the hospital rather than operating at arm's length. The authors argue that the employment relationship improves the hospital's bargaining power vis-à-vis insurers, based on their finding that the employment relationship is most often encountered when for-profit hospitals face concentrated insurers.

Miller and Wilson (2017) study hospital exit in a California market that-despite a rapidly growing population-experienced a shakeout period. They find that forprofit hospitals pull the exit "trigger" faster than do non-profits; the same is true for multi-hospital firms. These findings contribute additional evidence to the debate on whether governance matters for hospital operations.

Freedman et al. (2018) study hospitals' adoption of electronic medical record systems. Coordination on the same system facilitates information sharing on patients across hospitals: a social benefit. The authors uncover the perhaps surprising result that more competitive hospital markets exhibit more coordination. This result provides another potential concern about hospital mergers.

\footnotetext{
2 These figures were computed by dividing Research America $(2007,2016)$ estimates of U.S. R\&D in healthcare by National Science Foundation estimates of total U.S. R\&D.
} 
Horwitz et al. (2018) also study adoption of new technologies by hospitals, but in their case the technology is not as obviously productivity enhancing as electronic medical records. The new, invasive cardiac services on which the authors focus may be no more effective but are much more expensive and painful than the traditional medical therapies that are being replaced. In an experimental field such as healthcare, it is often hard to know how successful new technologies will be at the time of roll out. Horwitz et al. (2018) conduct a rare study of the determinants of the adoption of a technology that may ultimately turn out to be a bust.

Part II of the special issue is on health insurance (NAICS code 52411). It contains one article: Ho et al. (2018). This article stands on its own: it represents a significant methodological contribution to the empirical insurance literature. Using proprietary data on private insurance plans, the authors compare plans that instituted incentives for physicians to control costs with plans that did not have such incentives. A naive comparison suggests that the incentives generated large potential savings; but a closer tracking of consumer switches among plans reveals that some of the savings is due to more costly consumers' switching away from plans instituting incentives (presumably because of concerns about leaner services). The authors provide a method for decomposing insurer savings by carefully tracking consumers who stay versus those who switch plans.

Part III of the special contains four articles on the pharmaceutical industry (NAICS code 3254): Two articles measure the effect of generic entry on prices and other outcomes in drug markets. Olson and Wendling (2018) leverage a natural experiment that is provided by an exclusivity provision of the Hatch-Waxman Act of 1984 to identify the causal effect of entry on generic drug prices.

Scott Morton et al. (2018) study the market for biologic drugs: therapeutic proteins that are so complex that the United States barred generics (which are called biosimilars) from entering the market until recently. The authors turn to Europe, which has allowed biosimilar entry for over a decade. The unique dataset that the authors have compiled on this new market for biosimilars should spur a rich vein of follow-on research.

The last two articles focus on innovation in pharmaceutical markets: Kyle (2018) asks if innovation policy correctly targets rewards (patents, exclusivity, market share, etc.) to the most socially valuable pharmaceuticals. The author finds only a weak association between rewards and therapeutic value as assessed by French authorities. This finding suggests that some sort of policy mistake is being made: Either innovation policy is mis-targeted; or the French authorities have been mismeasuring value.

The final article, Kremer and Snyder (2018), revisits the analysis from their previous work (Kremer and Snyder 2015), which documented a fundamental bias that can lead a firm to prefer to develop an after-onset curative drug over a before-onset curative vaccine for the same disease. The contribution here tightens the theoretical bound on the deadweight loss from this bias; the authors document the dramatic sharpening of the resulting analysis in a calibration of demand for HIV pharmaceuticals that are sold on the global market. The calibration is also used to assess the effects of the introduction of reference pricing, a ban on price discrimination, and other policies. 


\section{Logistical Information}

The pool of articles considered for this special issue included both solicited manuscripts and manuscripts that were contributed in response to a call for papers. The accepted articles appearing in this special issue were subjected to review by an anonymous referee, a special-issue editor, and the general editor. The review process for the last article, coauthored by one of the special-issue editors, was conducted by the other special-issue editor.

We are proud to have assembled the nine articles that comprise this special issue. Many of the contributions are from established stars in the field; others were contributed by rising stars. The majority of authors would classify themselves as IO economists first who happen to study healthcare markets; but some contributors are healthcare economists first who have found value in the IO approach. In addition to the dataset assembled by Scott Morton et al. (2018 already mentioned, a majority of the articles in this special issue analyze unique, new data sources-which, along with the new methods and new theory that can be found in some of the articles, should provide valuable inputs into future research.

Acknowledgements The editors of this special issue are grateful to the General Editor, Lawrence White, for commissioning the special issue and for painstaking work evaluating and editing the papers that we conditionally accepted. We are also indebted to the many anonymous referees for providing expert evaluations and constructive suggestions on the submitted papers.

\section{References}

Chandra, A., Finkelstein, A., Sacarny, A., \& Syverson, C. (2016). Health care exceptionalism? Performance and allocation in the US health care sector. American Economic Review, 106, 2110-2144.

Freedman, S., Lin, H. \& Prince, J. (2018). Does competition lead to agglomeration or dispersion in EMR vendor decisions? Review of Industrial Organization. https://doi.org/10.1007/s11151-018-9624-1.

Gaynor, M., Ho, K., \& Town, R. J. (2015). The industrial organization of health-care markets. Journal of Economic Literature, 53, 235-284.

Ho, K., Pakes, A., \& Shepard, M. (2018). The evolution of health insurer costs in Massachusetts, 20102012. Review of Industrial Organization. https://doi.org/10.1007/s11151-018-9623-2.

Horwitz, J. R., Hsuan, C., \& Nichols, A. (2018). The role of hospital and market characteristics in invasive cardiac service diffusion. Review of Industrial Organization. https://doi.org/10.1007/s1115 1-018-9625-0.

Kremer, M., \& Snyder, C. M. (2015). Preventives versus treatments. Quarterly Journal of Economics, 130, 1167-1239.

Kremer, M., \& Snyder, C. M. (2018). Preventives versus treatments redux: Tighter bounds on distortions in innovation incentives with an application to the global demand for HIV pharmaceuticals. Review of Industrial Organization. https://doi.org/10.1007/s11151-018-9621-4.

Kyle, M. (2018). Are important innovations rewarded? Evidence from pharmaceutical markets. Review of Industrial Organization (in review).

McCarthy, I., \& Huang, S. (2017). Vertical alignment between hospitals and physicians as a bargaining response to commercial insurance markets. Review of Industrial Organization. https://doi. org/10.1007/s11151-017-9609-5.

Miller, K. S., \& Wilson, W. W. (2017). Governance structure and exit: Evidence from California hospitals. Review of Industrial Organization. https://doi.org/10.1007/s11151-017-9595-7. 
Olson, L. M., \& Wendling, B. W. (2018). Estimating the causal effect of entry on generic drug prices using Hatch-Waxman exclusivity. Review of Industrial Organization. https://doi.org/10.1007/s1115 1-018-9627-y.

Research America. (2007). 2007 Investment in U.S. Health Research. Arlington, Virginia. Retrieved October 18, 2017 http://www.researchamerica.org/-polls-publications/-us-investment-health-resea rch.

Research America. (2007). U.S. Investments in Medical and Health Research and Development, 20132015. Arlington, Virginia. Retrieved October 18, 2017, from http://www.researchamerica.org/-polls -publications/-us-investment-health-research.

Scherer, F. M. (2000). The pharmaceutical industry. In A. J. Culyer \& J. P. Newhouse (Eds.), Handbook of Health Economics (Vol. 1B, pp. 1297-1336). Amsterdam: North Holland.

Scott Morton, F. M., Stern, A. D., \& Stern, S. (2018). The impact of the entry of biosimilars: Evidence from Europe. Review of Industrial Organization (in review). 